\title{
Detailed comparison of bacterial communities during seasonal sludge bulking in a municipal wastewater treatment plant
}

\author{
Ping Wang a, Zhisheng $\mathrm{Yu}^{\mathrm{a}}{ }^{\text {* }}$, Rong Qi ${ }^{\mathrm{b}}$, Hongxun Zhang ${ }^{\mathrm{a}}$ \\ a College of Resources and Environment, University of Chinese Academy of Sciences, 19 A Yuquan Road, Beijing 100049, PR China \\ ${ }^{\mathrm{b}}$ Research Center for Eco-Environmental Sciences, Chinese Academy of Sciences, 18 Shuangqing Road, Beijing 100085, PR China
}

\section{A R T I C L E I N F O}

\section{Article history:}

Received 25 March 2016

Received in revised form

16 July 2016

Accepted 23 August 2016

Available online 24 August 2016

\section{Keywords:}

Wastewater treatment plant

Sludge bulking

Bacterial community

Filamentous bacteria

\begin{abstract}
A B S T R A C T
In this study, pyrosequencing combined with clone library analysis, qPCR, and fluorescent in situ hybridization (FISH) were performed to identify detailed changes of bacterial and filamentous bacterial communities in activated sludge (AS) in 3 types of typical AS samples: sludge bulking (B-AS), excessive bulking (EB-AS), and non-bulking (N-AS). Sludge bulking resulted in a decrease in total bacterial numbers from $(6.4 \pm 0.18) \times 10^{8}$ gene copies/mL in N-AS to $(2.4 \pm 0.22) \times 10^{8}$ in EB-AS and a decrease in bacterial diversity from 2757 OTUs in N-AS to 2217 OTUs in EB-AS. With the occurrence of sludge bulking, Actinobacteria and Firmicutes increased sharply, whereas Proteobacteria, which was the predominant phylum in N-AS, decreased markedly. In addition, Nitrospirae, a major lineage of the nitrite-oxidizing bacteria, had quite a low abundance in EB-AS (0.15\%), while it was relatively high in N-AS (1.17\%). On the other hand, filamentous bacteria accounted for $28.77 \%$ and $5.72 \%$ of total sequences in EB-AS and N-AS, respectively. More interestingly, 11 types of filamentous bacteria were always present in 3 types of typical AS samples from different stages of sludge bulking, and most of them enriched in EB-AS compared to NAS. It is noteworthy that, in addition to the frequently reported filamentous bacteria such as Candidatus M. parvicella and Tetrasphaera, novel filamentous species of Trichococcus might exist in this bulking WWTP. Our results reveal that sludge bulking are derived from diverse taxa, which expands previous understanding and provides new insight into the underlying complications of the bulking phenomenon in AS.
\end{abstract}

(c) 2016 Elsevier Ltd. All rights reserved.

\section{Introduction}

Sludge bulking is a global menace to wastewater treatment plants (WWTPs), since its occurrence often leads to poor sludge settleability and bad effluent quality (Martins et al., 2004). For example, in northern China, the problem occurs in over 50\% activated sludge (AS) WWTPs every year (Wang et al., 2014). In general, sludge bulking includes two types: filamentous bulking and nonfilamentous bulking caused by substantial accumulation of high viscosity polysaccharide substances secreted by Zoogloea (Eikelboom, 2000). Filamentous bulking accounts for more than $90 \%$ of sludge bulking. It is always caused by the overgrowth of filamentous bacteria, although they are essential parts of the floc populations in the AS process and their filaments form the backbone to which floc-forming bacteria adhere (Sezgin et al., 1978).

\footnotetext{
* Corresponding author.

E-mail address: yuzs@ucas.ac.cn (Z. Yu).
}

Substantial studies related to filamentous bulking have mainly focused on the ecophysiology of filamentous bacteria (Nielsen et al., 2009). For example, more than 30 different filament morphotypes were found in AS systems and their excessive growth was associated with sludge bulking (Nielsen et al., 2009). Among them, members of Actinobacteria such as Candidatus M. parvicella and Tetrasphaera were often the causative organisms of sludge bulking by plant surveys conducted around the world (Martins et al., 2004; Seviour et al., 2008). In addition to Actinobacteria, members of Proteobacteria such as Meganema perideroedes, Thiothrix eikelboomii, Leucothrix mucor, and type 021N (Nielsen et al., 2009; Asvapathanagul et al., 2015) could cause sludge bulking. Other filamentous members, such as Eikelboom morphotype 0803 of Chloroflexi, have also been found in AS WWTPs, and they have occasionally been associated with bulking incidences (Beer et al., 2002; Björnsson et al., 2002; Speirs et al., 2015). Moreover, the filamentous species of Bacteroidetes such as Haliscomenobacter hydrossis and Firmicutes such as Trichococcus Nostocoida limicola I have been isolated from AS (Nielsen et al., 2009; Liu et al., 2000; 
Muszyński, 2016), and they may have a slight effect on biomass settling properties (Kragelund et al., 2008). In fact, different types of filamentous bacteria may exist in WWTPs with or without obvious sludge bulking. For example, Guo and Zhang (2012) found most of these filamentous bacteria to exist in 14 global WWTPs without obvious sludge bulking.

Some studies related to filamentous bulking have been performed for solving sludge bulking problems (Martins et al., 2004). Sludge bulking is always controlled by nonspecific measures such as the addition of chlorine (Ramírez et al., 2000), ozone (Caravelli et al., 2006), metal salts (Agridiotis et al., 2007), and even cetyltrimethyl ammonium bromide (Guo et al., 2012). However, these nonspecific methods are not effective because they reduce the total numbers of bacterial populations and destroy the structure of flocforming bacteria, while the AS process heavily relies on highly complex microbial diversity for the removal of organic pollutants and nutrients from municipal and industrial wastewater to protect environmental and human health (Ju et al., 2014). Thus, developing a specific method is very effective for controlling filamentous bulking. The identification of the causative organisms of sludge bulking by comparing filamentous bacterial communities between bulking AS and non-bulking AS in the same WWTP is crucial for developing specific strategies to deal with it.

Bacterial communities in AS from bulking WWTPs have been intensively studied by traditional molecular methods such as denaturing gradient gel electrophoresis (DGGE) (El-Latif Hesham et al., 2011) and clone library analysis (Wang et al., 2014; Jin et al., 2011). However, changes in bacterial communities in AS from different stages of sludge bulking remain largely unstudied, which can be attributed to the lack of robust techniques needed to explore complex microbial communities. In recent years, highthroughput sequencing has become a popular method because it provides sufficient sequencing depth to cover complex microbial communities (Ye and Zhang, 2013; Zhang et al., 2012). To date, although Guo et al. have investigated filamentous bacterial communities in AS from 14 global WWTPs by high-throughput sequencing, none of these plants had any obvious bulking (Guo and Zhang, 2012). To the best of our knowledge, no study has been conducted using high-throughput sequencing to investigate the changes in bacterial and filamentous bacterial communities in AS during sludge bulking.

In the present study, high-throughput sequencing, clone library analysis, and fluorescence in situ hybridization (FISH) were used in conjunction to analyse in detail the bacterial and filamentous bacterial community structure of AS samples from different stages of sludge bulking in a municipal WWTP, to reveal the changes in the microbial community during sludge bulking, to evaluate the similarities and differences among different AS samples, and to compare the dominant bacteria and filamentous bacteria at different stages.

\section{Materials and methods}

\subsection{WWTP description and sample collection}

The investigated WWTP is a full-scale WWTP located in Beijing

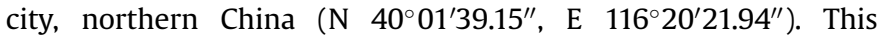
municipal WWTP serves more than 800,000 people. It consists of a conventional anaerobic/anoxic/aerobic $\left(\mathrm{A}^{2} / \mathrm{O}\right)$ system and an inverted $\mathrm{A}^{2} / \mathrm{O}$ system (anoxic/anaerobic/aerobic), each of which has a treatment design capacity of $200,000 \mathrm{~m}^{3} /$ day. In the past 4 years, each system has received mean wastewater flows of 225,000 $\mathrm{m}^{3}$ / day and has exhibited sludge bulking from late December to early May, with the inverted $\mathrm{A}^{2} / \mathrm{O}$ system exhibiting more excessive bulking.
All AS samples were collected from the same aeration tank of the inverted system from October 2010 to September 2011, resulting in a total of 12 AS samples. Among them, 3 types of typical AS samples from different stages of sludge bulking were collected: in December 2010 (when sludge bulking began to occur) (B-AS), February 2011 (when excessive sludge bulking was underway) (EBAS), and August 2011 (non-bulking in the WWTP) (N-AS). All samples were collected in triplicate and were kept in a portable icebox before being transported to the laboratory. Samples were stored at $-80{ }^{\circ} \mathrm{C}$ until DNA extraction and at $4{ }^{\circ} \mathrm{C}$ for FISH. In situ water quality parameters of each sample, including temperature, potential of hydrogen $(\mathrm{pH})$, and dissolved oxygen concentration (DO), were detected using a portable Hach sensION Multiparameter instrument (Hach Company, Loveland, CO, USA).

\subsection{DNA extraction, PCR-based 454 pyrosequencing, and clone library analysis}

AS samples $(10 \mathrm{~mL})$ were filtered using $0.22-\mu \mathrm{m}$ polycarbonate membranes (diameter, $47 \mathrm{~mm}$; Millipore Ltd., Bedford, UK). Total DNA of each sample was extracted in triplicate by the FastDNA SPIN kit for soil (Bio101 Systems, Carlsbad, CA, USA) according to the manufacturer's instructions. Final DNA products were suspended in TE buffer in a final volume of $50 \mu \mathrm{L}$ and stored at $-20^{\circ} \mathrm{C}$.

For 454 pyrosequencing, the hypervariable V4-V2 region of the bacterial 16S rRNA gene of the 3 types of typical AS samples was amplified. The primer set consisted of a forward primer (27F) (Lane, 1991) and a reverse primer (533R) (Weisburg et al., 1991) (Table S1) based on the Ribosomal Database Project pyrosequencing pipeline (http://pyro.cme.msu.edu/pyro/help.jsp). Barcodes that allow sample multiplexing during pyrosequencing were inserted between the 454 adapter sequence and the forward primers. Three replicates of $100 \mu \mathrm{L}$ PCR solutions were prepared for each sample using a Takara thermal cycler (TaKaRa, Tokyo, Japan) according to the manufacturer's instructions. PCR was performed under the following conditions: initial denaturation at $95{ }^{\circ} \mathrm{C}$ for $2 \mathrm{~min} ; 25$ cycles of $95{ }^{\circ} \mathrm{C}$ for $30 \mathrm{~s}, 55^{\circ} \mathrm{C}$ for $30 \mathrm{~s}$, and $72{ }^{\circ} \mathrm{C}$ for $60 \mathrm{~s}$; and final extension at $72{ }^{\circ} \mathrm{C}$ for $5 \mathrm{~min}$. Then, the PCR products of the 3 replicates were mixed and purified with the EZNA ${ }^{\circledR}$ Cycle-Pure Kit (Omega Bio-tek Inc., Doraville, GA, USA). After quantification using the NanoDrop ND-1000 UV-Vis spectrophotometer (NanoDrop Technologies, Wilmington, DE, USA), the PCR products of all samples were mixed to obtain equal concentrations of DNA fragments for each sample and were sent out for 454 pyrosequencing on the Roche 454 FLX Titanium platform (Roche, Nutley, NJ, USA) at the Genomic Research Center at Shanghai Majorbio Bio-pharm Biotechnology Co. Ltd., Shanghai, China.

For the construction of clone libraries, the 16S rRNA genes of the 3 types of typical AS samples were amplified using the Actinobacteria universal primer set S20/A19 (Table S1) (Stach et al., 2003). The conditions for PCR amplification were as follows: $94{ }^{\circ} \mathrm{C}$ for $7 \mathrm{~min} ; 30$ cycles of $94{ }^{\circ} \mathrm{C}$ for $60 \mathrm{~s}, 50{ }^{\circ} \mathrm{C}$ for $45 \mathrm{~s}$, and $72{ }^{\circ} \mathrm{C}$ for $60 \mathrm{~s}$; and a final elongation at $72{ }^{\circ} \mathrm{C}$ for $7 \mathrm{~min}$. The PCR amplification products of approximately $640 \mathrm{bp}$ were checked by electrophoresis in $1.0 \%(\mathrm{w} / \mathrm{v})$ agarose gel. Three separate reactions were conducted for each sample to minimize PCR bias in subsequent cloning steps, and all PCR products were purified using the TIANpure Mini Plasmid kit (Tiangen, Beijing, China) and then ligated into pGEM-T easy vector (Promega Corp., Madison, WI, USA). Plasmids were transformed into competent DH5 $\alpha$ cells via heat shock following the manufacturer's protocol (Invitrogen, Beijing, China). Cells were incubated at $37{ }^{\circ} \mathrm{C}$ overnight on agar plates containing ampicillin $(100 \mu \mathrm{g} / \mathrm{mL})$. White clones were selected for colony PCR. The positive clones were incubated for $12 \mathrm{~h}$ in Luria-Bertani broth containing ampicillin and then sent to Majorbio Bio-pharm Technology 
Co. Ltd. for sequencing.

\subsection{Statistical analysis}

Before analysis, the sequences from 454 pyrosequencing were cleaned by removing all sequences containing any ambiguous base ("N"), checking the completeness of the barcode and adapter, removing sequences shorter than $250 \mathrm{bp}$, eliminating chimeric sequences with the software Chimera Slayer (Haas et al., 2011), and cutting out the primers in all the pyrotags. The rest of sequences were trimmed and compared against the SILVA database (Pruesse et al., 2007) and BFB database (Guo and Zhang, 2012) via Mothur (http://www.mothur.org/wiki) (Schloss et al., 2009). Chao1 and Shannon indexes, and sample coverage were calculated with Mothur at 97\% similarity level. Optimized 16S rRNA gene sequences derived from 454 pyrosequencing were submitted to the NCBI Sequence Read Archive under accession number SRA052830.

Sequencing reads from the clone library were trimmed of vector sequences and inspected for ambiguities using Sequencher 4.1 software (Gene Codes, Ann Arbor, MI, USA). Chimeric sequences were detected using UCHIME and deleted (Edgar et al., 2011). The operational taxonomic unit (OTU) number was determined using Mothur at a 97\% similarity cutoff. Representative clones were selected from each OTU and compared with available 16S rRNA gene sequences in GenBank (http://www.ncbi.nlm. nih.gov) using the NCBI Blast program. Mothur was also used to calculate richness estimators and diversity indexes, including coverage and Chao1 and Shannon indexes. The sequences obtained in the present study have been deposited in GenBank as accession numbers JX442796JX442922.

All filamentous bacteria were substantiated by statistical testing according to the method of Klein et al. (2007). A type of filamentous bacteria was considered to be enriched in bulking AS when the probability of finding an individual of the filamentous bacteria of interest in bulking AS was higher than the probability of finding it in non-bulking AS. In the binomial framework, an individual either belongs to the population of interest or it does not. If the proportion of individuals of the population of interest in a sample is denoted as $\mathrm{p}$, the enrichment factor $(\omega)$ can be defined as pbulking AS/

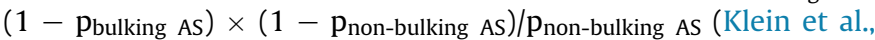
2007). Note that $\omega$ in the literature is referred to as the odds ratio (Sokal and Rohlf, 1995). We also assumed for filamentous bacteria that $\ln (\omega)$ was still normally distributed and that the measurement error associated with each sample was the same. Each sample was then treated as a replicate for testing by Student's $t$-distribution.

\subsection{Quantification of Candidatus M. parvicella and Actinobacteria}

qPCR was carried out using an $\mathrm{ABI} 7300$ sequence detection system (Applied Biosystems, Foster City, CA, USA). Data analyses were performed using the $A B I$ sequence detection software (version 1.3.1). The threshold cycle $(\mathrm{Ct})$ value is defined as the cycle number at which the measured fluorescence signal exceeds a threshold value. The $\mathrm{Ct}$ value was determined from dilution series of the target 16S rRNA gene with defined target molecule amounts by analysis of PCR kinetics using the ABI sequence detection software. The $\mathrm{Ct}$ value was proportional to the logarithm of the target molecule number. Thus, a $\mathrm{Ct}$ value measured in each sample could be converted to a target molecule number. The 16S rRNA gene was amplified in all 12 samples by using the following primer sets: 338F/518R for bacteria, Act920F3/Act1200R for Actinobacteria, and A17/S21 for Candidatus M. parvicella (Table S1) (Klammer et al., 2008; De Gregoris et al., 2011; Kaetzke et al., 2005). For amplification, each $25 \mu \mathrm{L}$ reaction volume contained $12.5 \mu \mathrm{L}$ of $2 \times$ SYBR Green mix (Thermo, San Jose, CA, USA), $1 \mu$ L of each primer (10 nM),
$1 \mu \mathrm{L}$ of sample DNA, $0.3 \mu \mathrm{L}$ BSA ( $10 \mathrm{mg} \mathrm{mL}^{-1}$ ), and $9.2 \mu \mathrm{L}$ of doubledistilled water. The temperature profile was as follows: $94^{\circ} \mathrm{C}$ for 3 min; 40 cycles of $94^{\circ} \mathrm{C}$ for $10 \mathrm{~s}, 60^{\circ} \mathrm{C}$ for $20 \mathrm{~s}, 72{ }^{\circ} \mathrm{C}$ for $20 \mathrm{~s}$, and $86^{\circ} \mathrm{C}$ for $15 \mathrm{~s}$ (for the measurement of the SYBR Green signal); and a final extension step $\left(72{ }^{\circ} \mathrm{C}\right.$ for $\left.7 \mathrm{~min}\right)$. The standard curves were generated by plotting the $\mathrm{Ct}$ values against $16 \mathrm{~S}$ rRNA gene copies of Candidatus M. parvicella and total bacteria in the template. All the measurements were performed in triplicate.

\subsection{Determination of filamentous bacteria using FISH}

The FISH technique was performed on the 3 types of typical AS samples. The list of oligonucleotide probes used in this study and their specificities are described in Table S1. The probes of EUB338mix (I-III) (Amann et al., 1990; Daims et al., 1999) were labeled at their $5^{\prime}$ ends by fluorescein isothiocyanate (Biomers, Ulm, Germany), and the Microthrix parvicella-specific probe of Mpa-all-1410 (Levantesi et al., 2006) was labeled at its $5^{\prime}$ end by sulphoindocyanine dyes (Biomers). The FISH procedure was conducted as described in detail elsewhere (Khan et al., 2013; Daims et al., 2004). After FISH by the probes Mpa-all-1410 and EUB338mix (I-III), the slides were then counterstained for $20 \mathrm{~min}$ with $100 \mathrm{ng} / \mu \mathrm{L}$ 2-(4-amidinophenyl)-6-indolecarbamidine dihydrochloride (DAPI, $20 \mu \mathrm{L}$ ) at room temperature. Finally, the slides were rinsed with cold water $\left(4^{\circ} \mathrm{C}\right)$ and air dried by blowing hard. A fluorescence microscope (Olympus, Tokyo, Japan) was used for recording fluorescence signals from the gene probes applied.

\section{Results}

\subsection{Dynamics of AS properties in a yearly cycle}

Fig. 1 shows the changes in sludge volume index (SVI), pH, DO, and temperature in a yearly cycle. In this investigated WWTP, the SVI began to surpass the value $150 \mathrm{~mL} / \mathrm{g}$ from December, indicating the beginning of sludge bulking. In February (SVI, $335 \mathrm{~mL} / \mathrm{g}$ ), excessive sludge bulking occurred. The entire period of sludge bulking lasted almost 6 months. The sludge settleability was categorized as "no bulking" from June to November, as indicated by the low SVI values $(<150 \mathrm{~mL} / \mathrm{g})$.

In the past several years, sludge bulking has shown a seasonal pattern. As shown in Fig. 1a, it is clear that the changes in SVI values had a direct relationship with temperature but had no relationship with $\mathrm{pH}$ or DO. Sludge bulking began to occur when the AS temperature was below $17{ }^{\circ} \mathrm{C}$, while the maximum atmospheric temperature was below $12^{\circ} \mathrm{C}$. When excessive bulking occurred, the AS temperature was $<13^{\circ} \mathrm{C}$, and the maximum and minimum atmospheric temperature was around 0 and $-12{ }^{\circ} \mathrm{C}$, respectively (Fig. 1b). Thus, temperature is one of the main environmental factors affecting sludge bulking.

\subsection{Diversity of microbial communities in AS}

As shown in Table 1,156,465 effective bacterial sequences were obtained through 454 pyrosequencing after trimming. For comparison at the same sequencing depth, 35,172 effective bacterial sequences were extracted from each sample to perform diversity analysis. The OTU numbers of B-AS, EB-AS, and N-AS were 2593, 2217 , and 2757, respectively. Diversity indices Chao1, Shannon, and coverage are listed in Table 1 at $97 \%$ similarity. The Chao1 index suggested that the estimated total species of B-AS, EB-AS, and N-AS samples were, respectively, $1.59,1.62$, and 1.57 times greater than those in the observed OTUs. The Shannon index showed that EB-AS had the lowest diversity in the 3 samples and N-AS had the highest diversity. Calculated coverage, which ranged from $96.82 \%$ to $97.42 \%$, 
(a)

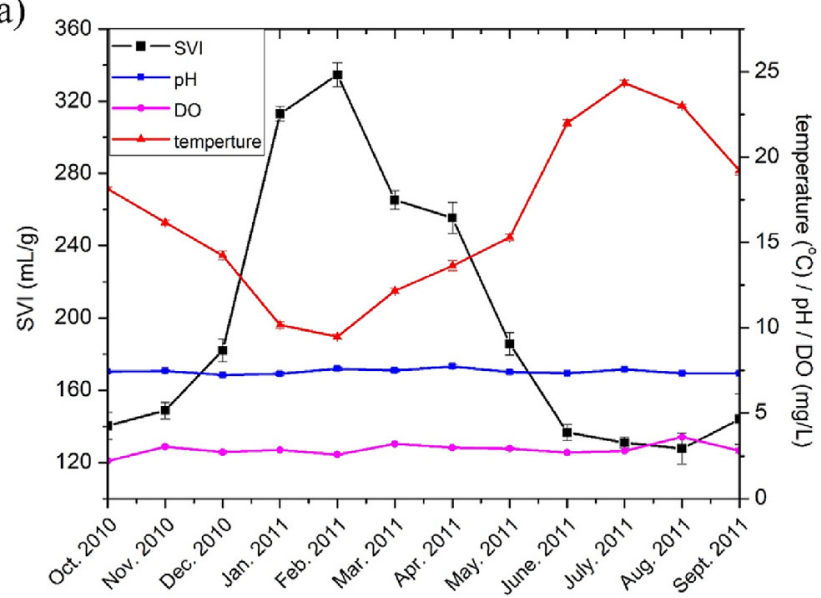

(b)

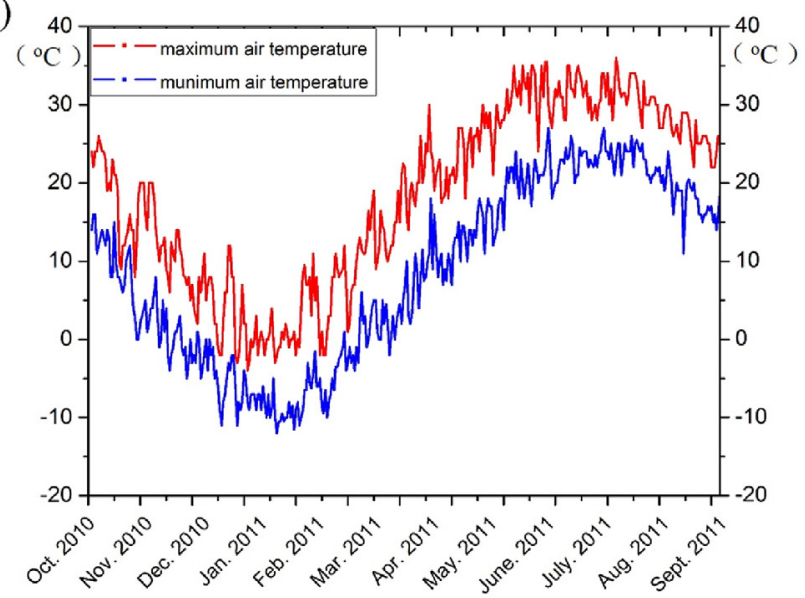

Fig. 1. Variations of SVI and operational parameters (a), and air temperature in a yearly sampling cycle (b) at the investigated WWTP. Abbreviations: SVI, sludge volume index; DO, dissolved oxygen.

revealed that, by 454 pyrosequencing, most communities were accounted for.

The phylogenetic classification of bacterial sequences from the 3 types of typical AS samples were assigned to different taxonomic levels (from genus to phylum) using the SILVA classifier at a 50\% threshold. Quite a large proportion of effective bacterial sequences in this study could not be assigned to any taxonomic level, although the V4 and V3 regions have been reported to display a very high number of correctly classified sequences in a previous study (Zhang et al., 2012). This indicated the extent of novel sequences captured by this study. Fig. S1 shows the unassigned sequence portions in the total community from the phylum level to the genus level. For all of them, the unassigned sequence portion in the bacterial community of EB-AS was the lowest, but that of N-AS was the highest, except at the family level.

Bacterial communities of 3 types of typical AS samples at the phylum level are summarized in Fig. 2a. There were, respectively, 32,26 , and 35 phyla in B-AS, EB-AS, and N-AS, including the candidate division. Although all communities contained the same major phyla, such as Proteobacteria, Actinobacteria, Chloroflexi, and Firmicutes, their respective abundances were very different. It is noteworthy that the phylum having the greatest increase accompanying the occurrence of sludge bulking was Actinobacteria. Actinobacteria predominated with $41.19 \%$ of total sequences in EB-AS, which accounted for $24.38 \%$ and $8.72 \%$ in B-AS and N-AS, respectively. Concurrent with the occurrence of sludge bulking, Firmicutes was the second most dramatically increased phylum, with abundances of $11.32 \%$ in EB-AS and $3.6 \%$ in N-AS. Similar to the study by Zhang et al. on bacterial communities in AS samples from 14 WWTPs of Asia and North America (Zhang et al., 2012), Proteobacteria was the predominant phylum in N-AS, accounting for $49.10 \%$ of total effective bacterial sequences in the present study. Interestingly, Proteobacteria clearly decreased with sludge bulking occurrence, with abundances of $32.21 \%$ and $28.28 \%$ in B-AS and EBAS, respectively. In addition, Bacteroidetes (6.49\%, 9.95\%, and $13.5 \%$ in B-AS, EB-AS, and N-AS, respectively) was also dominant, and its preponderance decreased with the occurrence of sludge bulking. What is interesting is that Chloroflexi $(17.54 \%, 3.11 \%$, and $11.68 \%$ in B-AS, EB-AS, and N-AS, respectively) clearly increased when sludge bulking began to occur and significantly decreased in excessive bulking AS. Planctomycetes, Acidobacteria, and Candidatus TM7 also increased when sludge bulking began to occur and decreased in excessive bulking AS. Remarkably, Nitrospirae, a major lineage of the nitrite-oxidizing bacteria vital for biological wastewater treatment, had quite a low abundance in B-AS and EB-AS $(0.2 \%$ and $0.15 \%$, respectively), while it was relatively high in N-AS $(1.17 \%)$.

Within Proteobacteria (as shown in Fig. 2b), Alphaproteobacteria (11.85\%) was the predominant class within Proteobacteria in EB-AS, and its abundance decreased clearly in N-AS (5.85\%). However, Betaproteobacteria (22.56\%) was the predominant class within Proteobacteria in N-AS, accounting for $8.63 \%$ and $10.5 \%$ in B-AS and EB-AS, respectively. In addition to Betaproteobacteria, Deltaproteobacteria was also dominant within Proteobacteria in N-AS (10.62\%), while its abundance was very low in B-AS (1.88\%) and EB-AS (0.63\%). Gammaproteobacteria was the dominant class in AS, while its abundance changed indistinctively with the occurrence of sludge bulking. Furthermore, Epsilonproteobacteria only occurred at very low levels $(0 \%, 0.48 \%$, and $0.69 \%$ in B-AS, EB-AS, and $\mathrm{N}-\mathrm{AS}$, respectively). These results indicated that sludge bulking resulted in a significant shift in the predominant Proteobacteria class from Betaproteobacteria and Deltaproteobacteria to Alphaproteobacteria.

At the order level (as shown in Table S2), 29 abundant ( $>1 \%$ in at least one AS sample) orders accounted for $80.17 \%, 85.66 \%$, and $77.43 \%$ of total sequences in B-AS, EB-AS, and N-AS, respectively. Our results clearly showed that the core bacteria in AS changed

Table 1

Comparison of phylotype coverage and diversity estimators using 454 pyrosequencing and clone library.

\begin{tabular}{|c|c|c|c|c|c|c|c|c|c|c|}
\hline \multirow[t]{2}{*}{ Sample } & \multicolumn{5}{|c|}{454 Pyrosequencing } & \multicolumn{5}{|c|}{ Clone library } \\
\hline & Reads & $\mathrm{OTU}^{\mathrm{a}}$ & Chao1 & Coverage $^{\mathrm{b}}$ & Shannon (nat) & Clones & $\mathrm{OTU}^{\mathrm{a}}$ & Chao1 & Coverage $^{\mathrm{b}}$ & Shannon (nat) \\
\hline B-AS & 35,172 & 2593 & $4123(3871,4373)^{c}$ & $97.03 \%$ & $6.19(6.16,6.21)^{\mathrm{d}}$ & 100 & 40 & $91(59,177)^{c}$ & $77.90 \%$ & $3.26(3.03,3.48)^{\mathrm{d}}$ \\
\hline EB-AS & 35,172 & 2217 & $3611(3274,3857)^{c}$ & $97.42 \%$ & $5.2(5.19,5.22)^{d}$ & 100 & 36 & $59(47,95)^{c}$ & $78.40 \%$ & $2.90(2.66,3.14)^{d}$ \\
\hline N-AS & 35,172 & 2757 & $4346(4110,4623)^{c}$ & $96.82 \%$ & $6.39(6.37,6.4)^{\mathrm{d}}$ & 100 & 43 & $130(86,234)^{c}$ & $74.10 \%$ & $3.61(3.43,3.80)^{\mathrm{d}}$ \\
\hline
\end{tabular}

${ }^{a}$ OTU was defined at $97 \%$ sequence similarity cutoff level.

b $[1-(\mathrm{n} / \mathrm{N})] \times 100 \%$.

c The confidence intervals for Chao1 estimators.

d The confidence intervals for shannon estimators. 

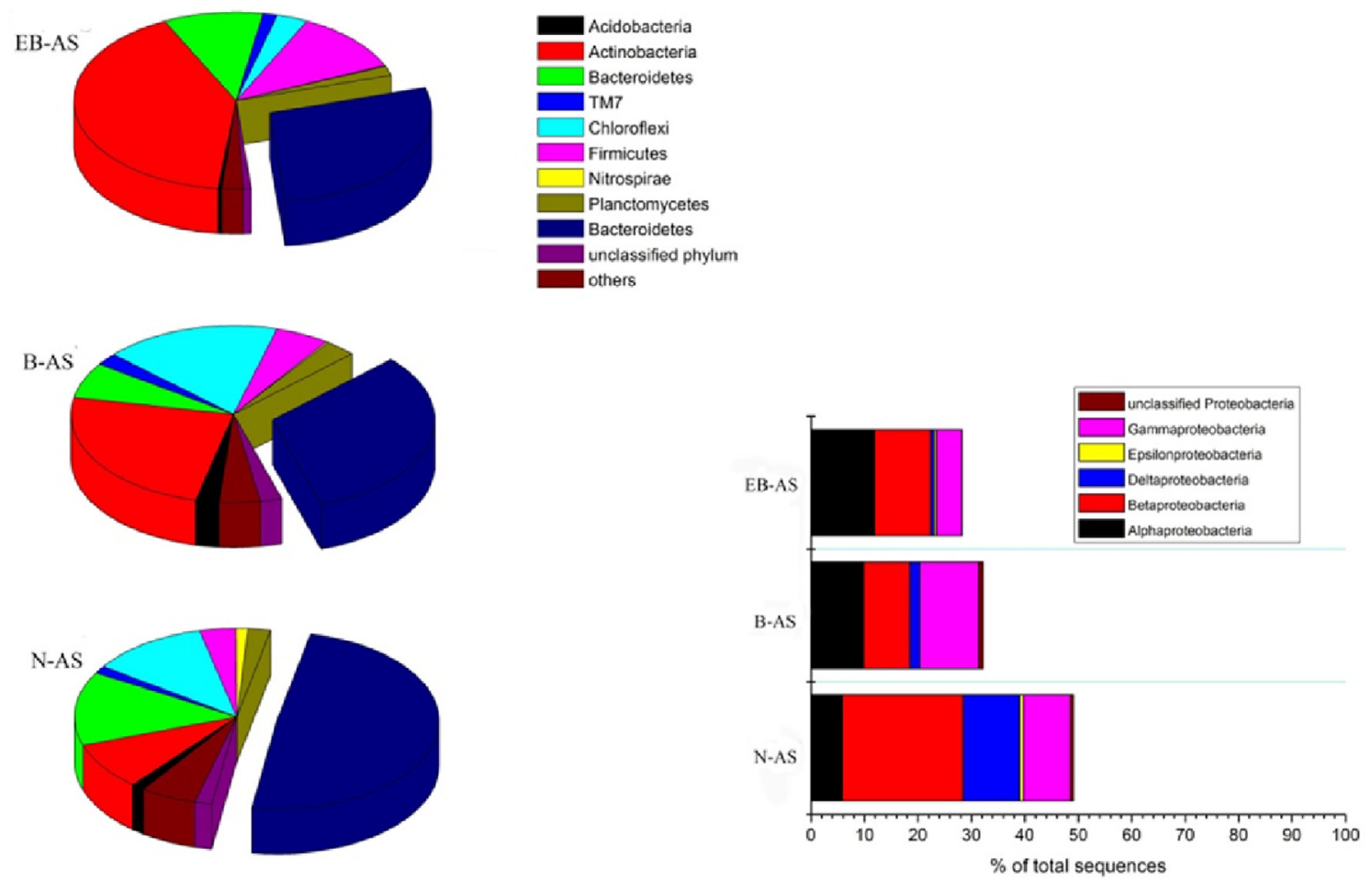

(a)

(b)

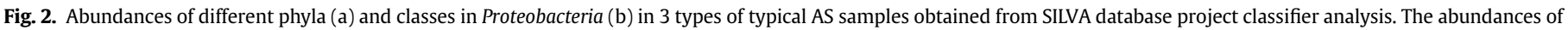
all those phyla were more than $1 \%$. EB-AS, B-AS, and N-AS represented excessive sludge bulking, sludge bulking, and non-bulking, respectively.

markedly with the occurrence of sludge bulking at the order level. For example, Acidimicrobiales (16.56\%), Micrococcales (11.58\%), and Burkholderiales (7.46\%) were the top 3 dominant orders in EB-AS, while their abundances were low in N-AS. However, the top 3 dominant orders in N-AS were Caldilineales (10.37\%), Xanthomonadales (6.44\%), and Rhizobiales (6.18\%).

\subsection{Similarities and differences in genus profiles during sludge bulking}

The top 20 genera in each sample (23 genera for 3 types of typical AS samples) were selected and compared for abundances in other samples, as shown in Fig. 3. In EB-AS, Candidatus M. parvicella (15.11\%) was the predominant genus, followed by Tetrasphaera (6.75\%), and Trichococcus (3.91\%). Most species of these 3 genera are considered filamentous bacteria. Meanwhile, these 3 genera also existed in N-AS; however, their abundances were much lower than in EB-AS. Moreover, Fodinibacter, Peptostreptococcaceae_Incertae_Sedis, and Rhodobacter were abundant in EB-AS (1.56-3.09\%), while their abundances were very low in N-AS $(0.28-0.6 \%)$. Most of them were fimilamentous bacteria and existed in bulking WWTPs (Nielsen et al., 2009). Unlike EB-AS, the predominant genus in N-AS was Thauera (6.83\%), followed by Anaerolineaceae (6.44\%), while these 2 genera decreased with the occurrence of sludge bulking. In addition to these 2 genera, Dokdonella, Haliangium, Flexibacter, Zoogloea, and Dechloromonas were abundant in N-AS $(1.22-2.50 \%)$, while their abundances also decreased with the occurrence of sludge bulking (0.12-0.44\% in EB-AS). In a previous study, Dokdonella was detected in AS from a WWTP in China (Li et al., 2012). Dechloromonas is also frequently reported as a phosphate-accumulating organism in biological phosphorus-removal reactors (Zhang et al., 2012; Liu et al., 2005). Species in the genus Zoogloea are known to form characteristic cell aggregates embedded in extracellular gelatinous matrices (Patrick et al., 2006) and are the main agents for the flocculation of AS (Rosselló-Mora et al., 1995). A very interesting phenomenon was that some bacteria related to nitrogen removal and transformation, such as Nitrosomonas and Nitrospira, decreased clearly with the occurrence of sludge bulking.

Just like at the phylum and order levels, the abundances of many genera in B-AS were between those of EB-AS and N-AS. This clearly showed that these microorganisms gradually changed with the occurrence and disappearance of sludge bulking. Furthermore, Fig. 3 also shows that the distribution of some genera depend on temperature. For example, the sequences assigned to some filamentous bacteria, such as Candidatus M. parvicella, Tetrasphaera, and Trichococcus, were found at high abundances in EB-AS $\left(10.2{ }^{\circ} \mathrm{C}\right.$ when sampling) and at low abundances in N-AS $\left(23.1^{\circ} \mathrm{C}\right.$ when sampling).

To further verify the changes in the composition of Actinobacteria during sludge bulking, we analysed the Actinobacteria community in different AS samples using clone library analysis. Diversity indices at $97 \%$ similarity of the 3 clone libraries are shown in Table 1 . Analysis of the clone library results at the genus level is shown in Fig. S2. Even though the 3 libraries contained the same major genera, such as Candidatus M. parvicella, Mycobacterium, and Janibacter, their abundances were very different. Candidatus $\mathrm{M}$. parvicella was the predominant genus in the EB-AS library (60\%), while its abundance accounted for $31.25 \%$ and $2.78 \%$ of the total Actinobacteria in B-AS and N-AS, respectively, which were concordant with the pyrosequencing results in the present study. In contrast, Mycobacterium had a higher abundance in the N-AS library (27.78\%) than in the other 2 libraries (B-AS: $3.13 \%$ and EB-AS: $2.82 \%$ ). Most species of this genus are pathogens causing enormous worldwide morbidity and mortality (Comas et al., 2010). 


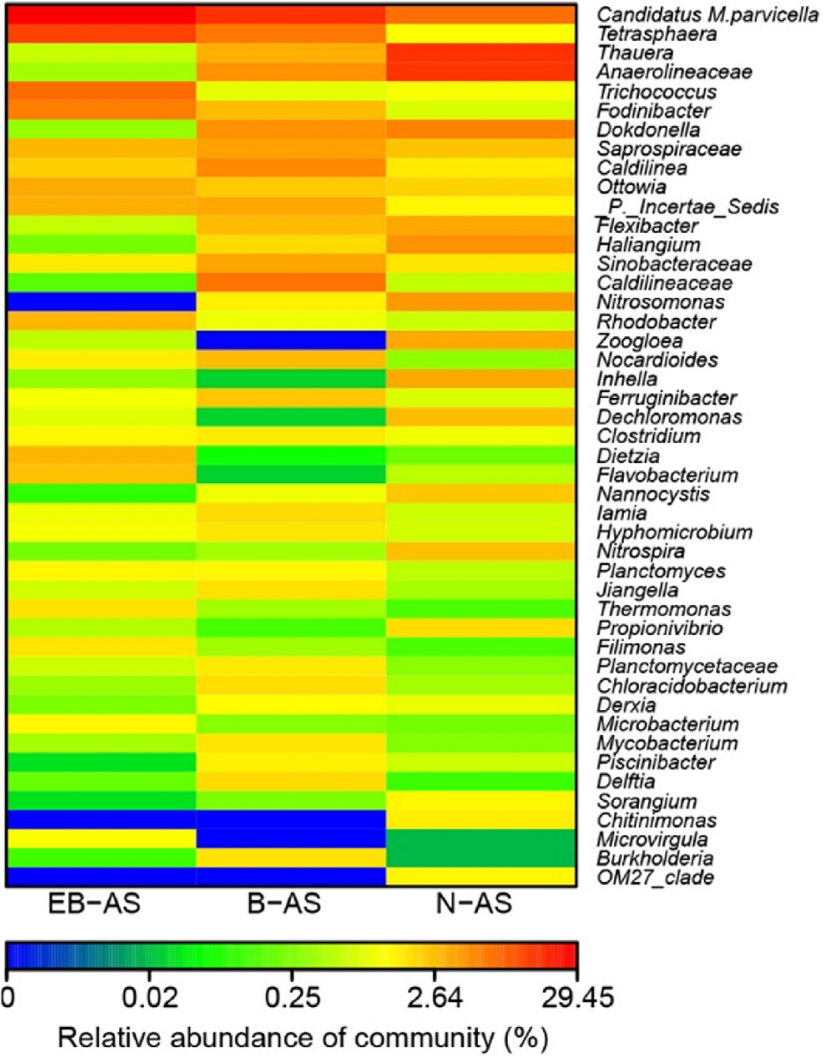

Fig. 3. Heatmap showing the top 20 abundant genera of bacterial community for each sample by 454 pyrosequencing. The abbreviations of the samples are the same as used in Fig. 2.

Why this species had such a high abundance in N-AS needs to be further analysed. Moreover, the abundance of Janibacter was found to be similar in the 3 libraries (EB-AS: $12.5 \%$, B-AS: $10.91 \%$, and NAS: $12.04 \%)$. Other genera, such as Amycolatopsis, Gordonia, and Tetrasphaera, represented $<5 \%$ of total Actinobacteria. However, we could not retrieve any representatives of certain Actinobacteria divisions such as Saccharothrix, Jiangella, and Arthrobacter in these 3 libraries. Nevertheless, they were retrieved in the pyrosequencing results in the present study, which might be due to greater sequencing depth.

\subsection{Dynamics of filamentous bacteria during sludge bulking}

A total of 105,516 effective bacterial sequences were further matched by the BFB database. The results suggested that filamentous bacteria (at $95 \%$ similarity cutoff) accounted for $28.77 \%, 8.77 \%$, and $5.72 \%$ of total sequences in EB-AS, B-AS, and N-AS, respectively (Fig. 4a). A previous study on filamentous bacteria in 14 globally distributed WWTPs showed that 2.71-15.65\% filamentous bacteria at a $95 \%$ similarity cutoff existed in AS samples without obvious bulking (Guo and Zhang, 2012). Given that the sludge samples investigated in this present study had excessive bulking, the abundance of total filamentous bacteria should be more than that of non-bulking sludge. It is noteworthy that Candidatus M. parvicella was the predominant filamentous bacteria in all 3 types of typical AS samples, accounting for $15.11 \%, 4.02 \%$, and $2.8 \%$, respectively, of the total sequences. In addition to Candidatus $\mathrm{M}$. parvicella, 10 other types of filamentous bacteria existed in all 3 AS samples. Among them, the subdominant in EB-AS was Nostocoida limicola II Tetrasphaera (3.75\%), followed by a few other major ( $>1 \%$

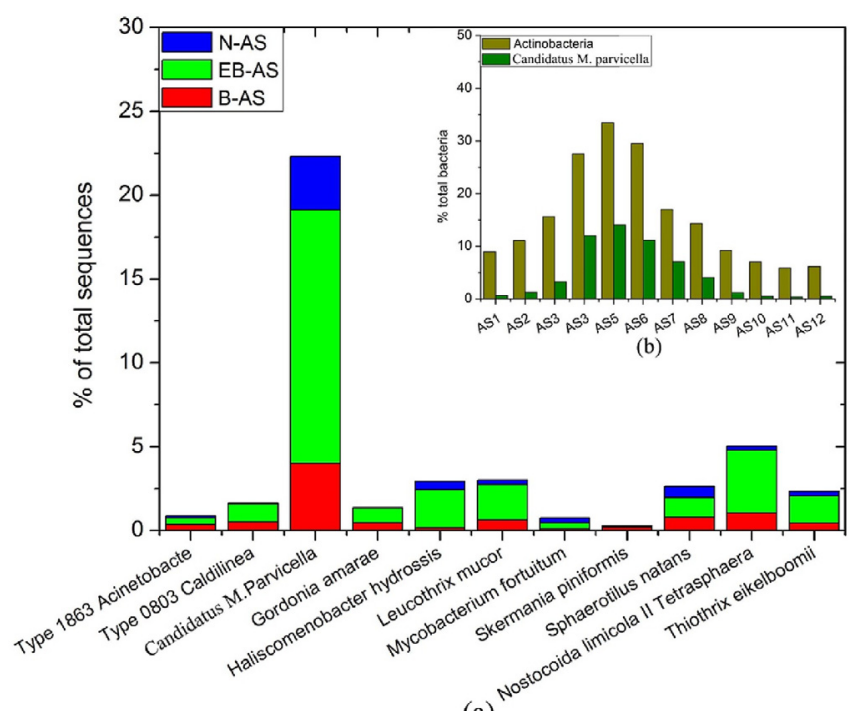

(a)

Fig. 4. Phylogenetic classification of filamentous bacteria community obtained from BFB database (a), and the abundances of Candidatus M. parvicella and Actinobacteria in the 12 AS samples (b), the abbreviations of the samples are the same as used in Fig. 2, AS1-AS12 represent monthly AS samples collected from October 2010 to September 2011.

abundance in EB-AS) species, including Haliscomenobacter hydrossis (2.27\%), Leucothrix mucor (2.11\%), Thiothrix eikelboomii (1.61\%), Sphaerotilus natans (1.19\%), and type 0803 Caldilinea (1.07\%). The abundances of the other filamentous bacteria were $<1 \%$ in all 3 AS samples. Except for Mycobacterium fortuitum, other 10 filamentous bacteria were enriched in bulking AS samples compared to nonbulking AS, leading to enrichment factors significantly above 1 (neutral point) (Table S4).

To detect the dynamics of the predominant filamentous bacteria during sludge bulking, qPCR was used to quantify Candidatus M. parvicella and Actinobacteria in AS samples from different periods in a yearly cycle (Fig. 4b). The maximum values of Candidatus $\mathrm{M}$. parvicella and Actinobacteria in total bacteria were respectively 14.03\% and $33.47 \%$ in February, while the minimum values were $0.33 \%$ and $5.87 \%$ in August. qPCR results showed that their abundances increased gradually with the occurrence of sludge bulking and decreased gradually with the disappearance of sludge bulking, which was consistent with the results of pyrosequencing and clone library analysis in the present study. Moreover, qPCR results also clearly showed that sludge bulking resulted in a decrease in total bacterial number, because the minimum and maximum values of the copy numbers of bacteria were $(2.4 \pm 0.22) \times 10^{8}$ and $(6.4 \pm 0.18) \times 10^{8}$ gene copies per millilitre AS in EB-AS and N-AS, respectively.

To further observe the changes in filamentous bacteria in AS from different stages of sludge bulking, the morphologies of the target group in the 3 types of typical AS samples were tested using FISH. Fig. 5 (A1-A3) shows that filamentous bacteria exist in all 3 AS samples but their numbers and morphologies are very different. Fig. 5 (B1-B3) shows that Microthrix parvicella also exists in all 3 samples, but it is interesting that its morphology varies between EB-AS and N-AS. Moreover, EB-AS clearly had the largest numbers and the longest extended filaments of Microthrix parvicella, while its filaments in N-AS were considerably short. As shown in Fig. 5 (C1-C3), Microthrix parvicella is predominant among various filamentous bacteria, while there are other filamentous bacteria in EBAS. 

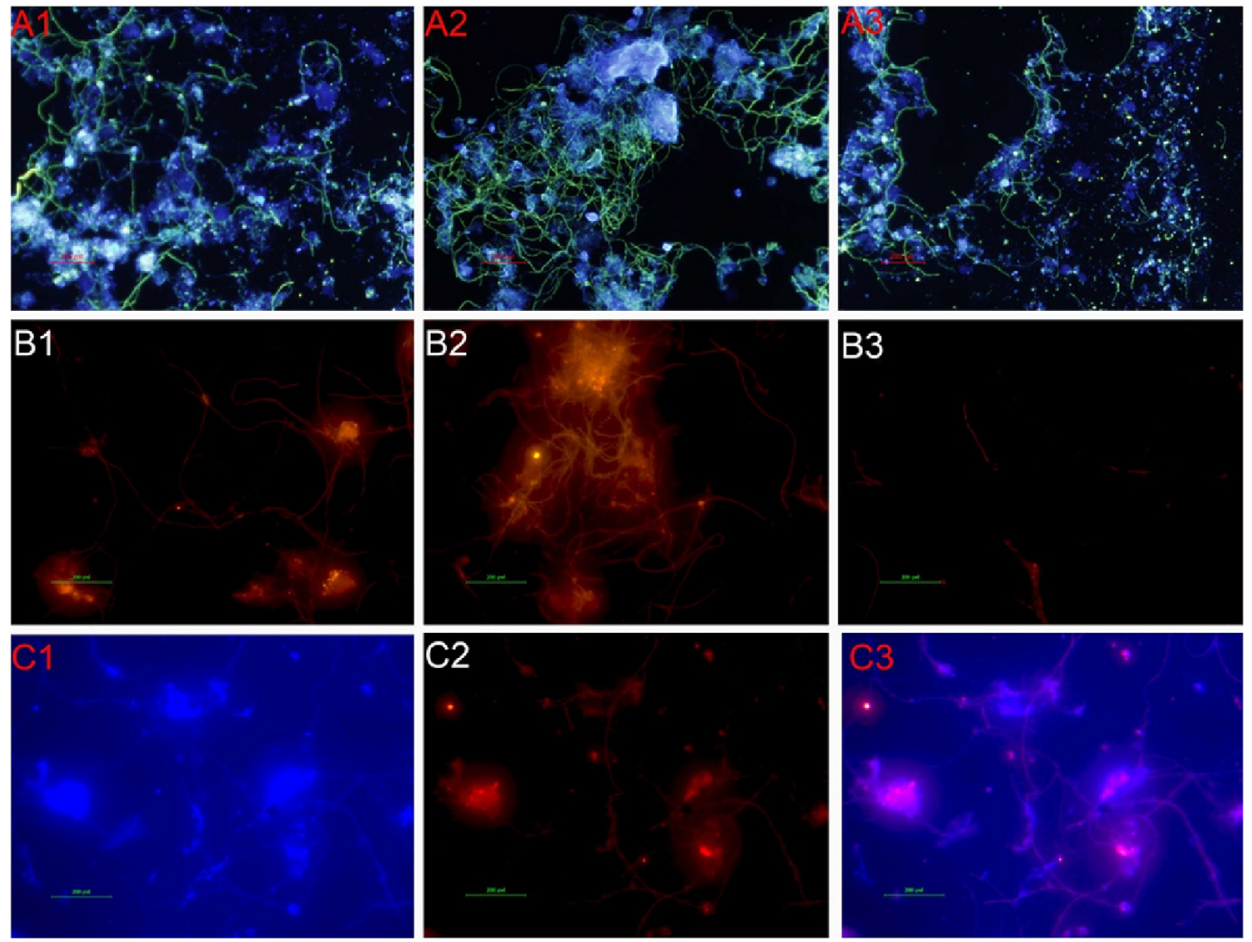

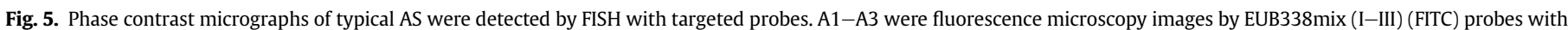

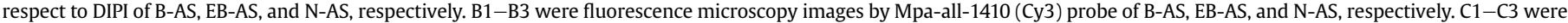

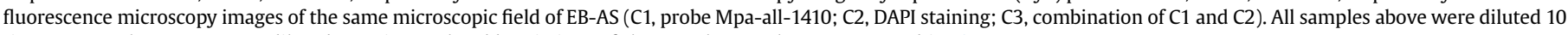
times except that $\mathrm{C} 1-\mathrm{C} 3$ was diluted 100 times. The abbreviations of the samples are the same as used in Fig. 2.

\section{Discussion}

Here, we aimed to identify the detailed changes in bacterial and filamentous bacterial communities during sludge bulking in a municipal WWTP on the basis of high-throughput sequencing profiles of community structure, in conjunction with clone library analysis, qPCR, and FISH. Thus far, bacterial communities in AS have always been detected using a single molecular method such as high-throughput sequencing (Zhang et al., 2012; Ye et al., 2011; Hu et al., 2012) or DGGE (El-Latif Hesham et al., 2011). To the best of our knowledge, the present study is the first application of PCR-based methods, including high-throughput sequencing, traditional sequencing (clone library), and an in situ method (FISH) to characterize and compare bacterial and filamentous bacterial communities in typical AS samples representing different stages of sludge bulking. The use of more than one molecular technique to characterize the microbial community can help overcome the inherent limitations of either individual technique, such as primer and methodological biases.

\subsection{Dynamics of bacterial communities during sludge bulking}

With regard to the identification of bacterial communities in AS by high-throughput sequencing, previous studies mainly focused on community structure in AS samples from different WWTPs (Zhang et al., 2012; Hu et al., 2012). Unlike those studies, the present study focused on the detailed changes of bacterial communities in AS samples during sludge bulking. Our results clearly showed that there were considerable similarities (e.g., shared bacteria) and differences (marked changes in the abundances of shared bacteria) in the bacterial communities during sludge bulking. Proteobacteria, Actinobacteria, Chloroflexi, Firmicutes, and Bacteroidetes were found in the 3 types of typical AS samples, and their abundances changed considerably with the occurrence of sludge bulking. Similar to a previous study on the bacterial community structure of AS samples from a bulking municipal WWTP in northern China using a cloning method (Wang et al., 2014), our present study showed that sludge bulking resulted in a significant shift in bacterial compositions from a dominance of Proteobacteria to a dominance of Actinobacteria. Yet another study on seasonal microbial variations of AS from a full-scale WWTP over 4 years using metagenomic analysis showed Proteobacteria to be the predominant phylum in winter and summer samples and Actinobacteria to be usually higher in winter than in summer (Ju et al., 2014). Thus, sludge bulking, rather than seasonal changes, was considered the main reason underlying the significant shift in bacterial compositions. Further analysis showed that an increase in Actinobacteria along with the occurrence of sludge bulking results from the proliferation of Candidatus M. parvicella and Tetrasphaera. Meanwhile, an earlier study proved that in most plants, the separation process is eventually disrupted by excessive growth of filamentous Actinobacteria, including Candidatus M. parvicella and Tetrasphaera, leading to the problem of sludge bulking (Seviour et al., 2008). Many studies have shown that many Proteobacteria members are always present and play a key role in the functioning of municipal WWTPs (Oehmen et al., 2007; Nielsen et al., 2010). When sludge bulking occurs, the overgrowth of filamentous bacteria could result in a decrease in non-filamentous bacteria, making these non-filamentous bacteria susceptible to being washed out from WWTPs (Wang et al., 2014). Similar to the report of Wang et al. (2014), our 454 pyrosequencing results indicated that sludge bulking resulted in a significant shift in Proteobacteria compositions from a dominance of Betaproteobacteria to that of Alphaproteobacteria. A detailed analysis showed that the abundance of Alphaproteobacteria increased considerably with the occurrence of sludge bulking because of the increase in some functional bacteria such as 
Rhodobacter (Kong et al., 2007), whereas the abundance of Betaproteobacteria decreased markedly with the occurrence of sludge bulking due to the decrease in certain functional bacteria such as Thauera, Dechloromonas, Zoogloea, and Nitrosomonas (Wang et al., 2014). However, Deltaproteobacteria was also a dominant class within Proteobacteria in the non-bulking AS in the present study, and its abundance decreased markedly with the occurrence of sludge bulking owing to the decrease in Haliangium. Studies using DGGE and clone library analysis have shown that Alphaproteobacteria are always considerably abundant when excessive sludge bulking occurs (Wang et al., 2014; El-Latif Hesham et al., 2011).

The phylum Firmicutes was found to follow closely as the second most dramatically increased phylum during sludge bulking, and filamentous species of this phylum have been found in WWTPs by culture studies (Liu et al., 2002). Further analysis showed an increase in Firmicutes concomitant with the occurrence of sludge bulking because of the proliferation of Trichococcus, most species of which are filamentous bacteria (Zhang et al., 2012). Similar to previous studies on AS using high-throughput sequencing (Zhang et al., 2012) and cloning (Blackall et al., 1998), Bacteroidetes and Chloroflexi were dominant in non-bulking AS in the present study. However, our findings showed that they decreased to some extent when sludge bulking occurred, owing to the decrease in Anaerolineaceae (belonging to Chloroflexi) and Flexibacter (belonging to Bacteroidetes). An important phenomenon was that some functional bacteria related nitrogen removal and transformation, such as Nitrosomonas and Nitrospira, markedly decreased with the occurrence of sludge bulking. Thus, our results provide a comprehensive understanding of the changes in bacterial communities in AS samples from different stages of sludge bulking, demonstrating that sludge bulking resulted in a significant shift in bacterial composition from a preponderance of functional bacteria to that of filamentous bacteria.

\subsection{Biological and environmental factors causing sludge bulking}

Although Zhang et al. have profiled bulking and foaming bacteria in AS by high-throughput sequencing, those plants had no obvious bulking (Guo and Zhang, 2012). This is the first study to show the changes in filamentous bacterial communities in AS samples from different stages of sludge bulking. The results from more than one molecular method indicated that sludge bulking was caused by the overgrowth of several types of filamentous bacteria. A previous study has identified the 2 dominant groups of filamentous bacteria (Chloroflexi and Microthrix parvicella) in AS samples from filamentous bulking WWTPs (Wágner et al., 2015). Furthermore, Candidatus M. parvicella was confirmed to be the causative filamentous bacteria for sludge bulking in the investigated WWTP because its abundance gradually increased and its filaments became longer with the occurrence of sludge bulking. Candidatus M. parvicella is a filamentous bacterium occurring mainly in activated sludge environments, and it has been identified as the most dominant filamentous microorganism in biological nutrient removal plants worldwide (Jenkins et al., 2004; Martins et al., 2004). The Long chain fatty acid (LCFA) content in wastewater influents is a significant influencing factor promoting the growth of Candidatus M. parvicella (Dunkel et al., 2015). This organism is responsible for bulking (Martins et al., 2004; Muller et al., 2012) and might be the most frequent in bulking situations (Rossetti et al., 2005; Guo et al., 2013; Santos et al., 2015). Surprisingly, Candidatus M. parvicella was considerably abundant in the non-bulking AS (3.20\%), and a previous study showed that $>3 \%$ Candidatus M. parvicella in AS could cause foaming problems in WWTPs (Kaetzke et al., 2005). Interestingly, our FISH results demonstrated that excessive bulking AS had the largest numbers and the longest extended filaments of Microthrix parvicella in all 3 types of typical AS samples, whereas the filaments of this kind of filamentous bacteria in non-bulking AS were considerably short. Filaments extending from the flocs have been found to correspond to a high SVI (Westlund et al., 1996), and the short filaments of Microthrix parvicella have been indicated to not have a negative effect on sludge settleability (Knoop and Kunst, 1998). These findings explain why Candidatus M. parvicella was considerably abundant in non-bulking AS from the investigated WWTP.

In this study, in addition to Candidatus M. parvicella, Tetrasphaera was also found to be abundant in excessive bulking AS, and its abundance increased markedly with the occurrence of sludge bulking. Noticeably, Nostocoida limicola II Tetrasphaera comprised up to $56 \%$ of total Tetrasphaera in excessive bulking AS. Most published survey data have shown that this kind of filamentous bacteria often exists in bulking plants around the world (Seviour et al., 2008). A very interesting phenomenon was that Trichococcus increased considerably with the occurrence of sludge bulking according to the results by the SILVA database $(3.91 \%$ and $0.28 \%$ of sequences in EB-AS and N-AS, respectively. Fig. 3). Liu et al. showed Trichococcus Nostocoida limicola I to be a type of filamentous bacteria in AS samples (Liu et al., 2000), but it was not detected by the BFB database. Therefore, we considered that other novel filamentous bacteria of Trichococcus might exist in AS samples in the investigated bulking WWTP. This is an interesting aspect worth investigating in future studies. In addition, Haliscomenobacter hydrossis and Leucothrix mucor also increased considerably when excessive sludge bulking occurred. The occurrence of these 2 filamentous groups has been proved in bulking AS samples by culturedependent analysis (Nielsen et al., 2009). Moreover, other filamentous bacteria (Thiothrix eikelboomii, Sphaerotilus natans, and Type 0803 Caldilinea) were present in all 3 AS samples, and their abundances increased to some extent when excessive sludge bulking occurred. Our current results provide us detailed changes in filamentous bacterial community during sludge bulking, although it is still difficult to draw firm conclusions on the roles that the species of filamentous bacteria might have in sludge bulking. More attention to their roles should be tested in further investigations.

According to the relationship of SVI and temperature, sludge bulking seemed to have a direct relationship with temperature. In this investigated WWTP, sludge bulking often occurred in winter and spring with low temperature in every year. This might be because municipal wastewater abounds in lipids, and low temperatures decrease lipid solubility and inhibit the lipid uptake of non-specialized heterotrophic bacteria, enabling certain hydrophobic microorganisms to outcompete other lipid-utilizing organisms for oleic acid in WWTPs. For example, Candidatus M. parvicella, which plays a major role in sludge bulking, was considered to grow better in plants in colder climates (Seviour et al., 2008). Meanwhile, a study on a foaming-prone full-scale biogas plant containing the filamentous bacterium Candidatus M. parvicella showed that a moderate temperature increase might help to control the Candidatus M. parvicella abundance (Lienen et al., 2014). Other filamentous bacteria related to sludge bulking, such as Tetrasphaera and Trichococcus, are also considered as psychrotolerant mesophiles, growing easily in cold seasons (Seviour et al., 2008; Zhang et al., 2012).

\section{Conclusion}

Detailed comparison of bacterial and filamentous bacterial communities during seasonal sludge bulking in a municipal wastewater treatment plant were investigated using a serious of methods. The main findings showed that: (1) sludge bulking 
resulted in a marked shift in bacterial compositions from a preponderance of functional bacteria to that of filamentous bacteria, mainly because Candidatus M. parvicella, Tetrasphaera, and Trichococcus were predominant in EB-AS, and Thauera, Dechloromonas, and Nitrosomonas were predominant in N-AS. (2) Eleven types of filamentous bacteria existed in 3 types of typical AS samples from different stages of sludge bulking. As expected, their abundances increased with the occurrence of sludge bulking. In addition to the frequently reported filamentous bacteria such as Candidatus M. parvicella and Tetrasphaera, novel filamentous species of Trichococcus might exist in the bulking WWTP. (3) Candidatus M. parvicella and temperature were revealed as the main biological and environmental factors causing bulking, thereby providing a theoretical basis for developing specific strategies to control sludge bulking in northern China.

\section{Acknowledgements}

This work was supported by the Main Direction Program of Knowledge Innovation of Chinese Academy of Sciences (No. KZCX2YW-JC407-2) and the Strategic Priority Research Program (B) of the Chinese Academy of Sciences (XDB15010200). We would like to thank Yaming Li for providing the samples.

\section{Appendix A. Supplementary data}

Supplementary data related to this article can be found at http:// dx.doi.org/10.1016/j.watres.2016.08.050.

\section{References}

Agridiotis, V., Forster, C., Carliell-Marquet, C., 2007. Addition of Al and Fe salts during treatment of paper mill effluents to improve activated sludge settlement characteristics. Bioresour. Technol. 98 (15), 2926-2934.

Amann, R.I., Binder, B.J., Olson, R.J., Chisholm, S.W., Devereux, R., Stahl, D.A., 1990 Combination of 16S rRNA-targeted oligonucleotide probes with flow cytometry for analyzing mixed microbial populations. Appl. Environ. Microbiol. 56 (6), 1919-1925.

Asvapathanagul, P., Olson, B.H., Gedalanga, P.B., Hashemi, A., Huang, Z., La, J., 2015 Identification and quantification of Thiothrix eikelboomii using QPCR for early detection of bulking incidents in a full-scale water reclamation plant. Appl. Microbiol. Biotechnol. 99 (9), 1-13.

Beer, M., Seviour, E.M., Kong, Y., Cunningham, M., Blackall, L.L., Seviour, R.J., 2002 Phylogeny of the filamentous bacterium Eikelboom Type 1851, and design and application of a 16S rRNA targeted oligonucleotide probe for its fluorescence in situ identification in activated sludge. FEMS Microbiol. Lett. 207 (2), 179-183.

Björnsson, L., Hugenholtz, P., Tyson, G.W., Blackall, L.L., 2002. Filamentous Chloroflexi (green non-sulfur bacteria) are abundant in wastewater treatment processes with biological nutrient removal. Microbiology 148 (8), 2309-2318.

Blackall, L.L., Burrell, P.C., Gwilliam, H., Bradford, D., Bond, P.L., Hugenholtz, P., 1998 The use of $16 \mathrm{~S}$ rDNA clone libraries to describe the microbial diversity of activated sludge communities. Water Sci. Technol. 37 (4), 451-454.

Caravelli, A., Giannuzzi, L., Zaritzky, N., 2006. Effect of ozone on filamentous bulking in a laboratory scale activated sludge reactor using respirometry and INTdehydrogenase activity. J. Environ. Eng. 132 (9), 1001-1010.

Comas, I., Chakravartti, J., Small, P.M., Galagan, J., 2010. Human T cell epitopes of Mycobacterium tuberculosis are evolutionarily hyperconserved. Nat. Genet. 42 (6), 498-503.

Daims, H., Brühl, A., Amann, R., Schleifer, K., Wagner, M., 1999. The domain-specific probe EUB338 is insufficient for the detection of all Bacteria: development and evaluation of a more comprehensive probe set. Syst. Appl. Microbiol. 22 (3), 434-441.

Daims, H., Holger, K., Wagner, M., Stoecker, K., 2004. Fluorescence in situ hybridization for the detection of prokaryotes. Mol. Microb. Ecol. 192.

De Gregoris, T.B., Aldred, N., Clare, A.S., Burgess, J.G., 2011. Improvement of phylumand class-specific primers for real-time PCR quantification of bacterial taxa. J. Microbiol. Methods 86 (3), 351-356.

Dunkel, T., El, D.L.G., Schönsee, C.D., Hesse, T., Jochmann, M., Wingender, J. Denecke, M., 2015. Evaluating the influence of wastewater composition on the growth of Microthrix parvicella by GCxGC/qMS and real-time PCR. Water Res. $88,510-523$

Edgar, R.C., Haas, B.J., Clemente, J.C., Quince, C., Knight, R., 2011. UCHIME improves sensitivity and speed of chimera detection. Bioinformatics 27 (16), 2194-2200.

Eikelboom, D.H., 2003. Process Control of Activated Sludge Plants by Microscopic Investigation. IWA Publishing, London, United Kingdom, p. 143.
El-Latif Hesham, A., Qi, R., Yang, Min, 2011. Comparison of bacterial community structures in two systems of a sewage treatment plant using PCR-DGGE analysis. J. Environ. Sci. 23 (12), 2049-2054.

Guo, F., Zhang, T., 2012. Profiling bulking and foaming bacteria in activated sludge by high throughput sequencing. Water Res. 46 (8), 2772-2782.

Guo, J., Peng, Y., Wang, Z., Yuan, Z., Yang, X., Wang, S., 2012. Control filamentous bulking caused by chlorine-resistant type $021 \mathrm{~N}$ bacteria through adding a biocide CTAB. Water Res. 46 (19), 6531-6542.

Guo, J., Peng, Y., Yang, X., Gao, C., Wang, S., 2013. Combination process of limited filamentous bulking and nitrogen removal via nitrite for enhancing nitrogen removal and reducing aeration requirements. Chemosphere 91 (1), 68-75.

Haas, B.J., Gevers, D., Earl, A.M., Feldgarden, M., Ward, D.V., Giannoukos, G., Ciulla, D., Tabbaa, D., Highlander, S.K., Sodergren, E., Methe, B., DeSantis, T.Z. Petrosino, J.F., Knight, R., Birren, B.W., Human Microbiome, C, 2011. Chimeric $16 \mathrm{~S}$ rRNA sequence formation and detection in Sanger and 454-pyrosequenced PCR amplicons. Genome Res. 21 (3), 494-504.

Hu, M., Wang, X., Wen, X., Xia, Y., 2012. Microbial community structures in different wastewater treatment plants as revealed by 454-pyrosequencing analysis. Bioresour. Technol. 117, 72-79.

Jenkins, D., Richard, M.G., Daigger, G.T. 2004. Manual on the Causes and Control of Activated Sludge Bulking, Foaming, and Other Solids Separation Problems, third ed. Lewis Publishers.

Jin, D., Wang, P., Bai, Z., Wang, X., Peng, H., Qi, R., Yu, Z., Zhuang, G., 2011. Analysis of bacterial community in bulking sludge using culture-dependent and -independent approaches. J. Environ. Sci. China 23 (11), 1880-1887.

Ju, F., Guo, F., Ye, L., Xia, Y., Zhang, T., 2014. Metagenomic analysis on seasonal microbial variations of activated sludge from a full-scale wastewater treatment plant over 4 years. Environ. Microbiol. Rep. 6 (1), 80-89.

Kaetzke, A., Jentzsch, D., Eschrich, K., 2005. Quantification of Microthrix parvicella in activated sludge bacterial communities by real-time PCR. Lett. Appl. Microbiol. 40 (3), 207-211.

Khan, M.A., Mohsin, J., Faheem, S.M., 2013. Monitoring microbial diversity of a fullscale municipal wastewater treatment plant in Dubai. APCBEE Procedia 5, $102-106$.

Klammer, S., Knapp, B., Insam, H., Dell'Abate, M.T., Ros, M., 2008. Bacterial community patterns and thermal analyses of composts of various origins. Waste Manag. Res. 26 (2), 173-187.

Klein, A.N., Frigon, D., Raskin, L., 2007. Populations related to Alkanindiges, a novel genus containing obligate alkane degraders, are implicated in biological foaming in activated sludge systems. Environ. Microbiol. 9 (8), 1898-1912.

Knoop, S., Kunst, S., 1998. Influence of temperature and sludge loading on activated sludge settling, especially on Microthrix parvicella. Water Sci. Technol. 37 (4), 27-35.

Kong, Y., Xia, Y., Nielsen, J.L., Nielsen, P.H., 2007. Structure and function of the microbial community in a full-scale enhanced biological phosphorus removal plant. Microbiology 153 (12), 4061-4073.

Kragelund, C., Levantesi, C., Borger, A., Thelen, K., Eikelboom, D., Tandoi, V., Kong, Y., Krooneman, J., Larsen, P., Thomsen, T.R., 2008. Identity, abundance and ecophysiology of filamentous bacteria belonging to the Bacteroidetes present in activated sludge plants. Microbiology 154 (3), 886.

Lane, D., 1991. 16S/23S rRNA sequencing. In: Nucleic Acid Techniques in Bacterial Systematics, pp. 125-175.

Levantesi, C., Rossetti, S., Thelen, K., Kragelund, C., Krooneman, J., Eikelboom, D., Nielsen, P.H., Tandoi, V., 2006. Phylogeny, physiology and distribution of 'Candidatus Microthrix calida', a new Microthrix species isolated from industrial activated sludge wastewater treatment plants. Environ. Microbiol. 8 (9), 1552-1563.

Li, Y., Zhang, J., Chen, Q., Yang, G., Cai, S., He, J., Zhou, S., Li, S.P., 2012. Dokdonella kunshanensis sp. nov., isolated from activated sludge and emended description of the genus Dokdonella. Int. J. Syst. Evol. Microbiol. 63 (4), 1519-1523.

Lienen, T., Kleyböcker, A., Verstraete, W., Würdemann, H., 2014. Moderate temperature increase leads to disintegration of floating sludge and lower abundance of the filamentous bacterium Microthrix parvicella in anaerobic digesters. Water Res. 65, 203-212.

Liu, J.R., Burrell, P., Seviour, E.M., Soddell, J.A., Blackall, L.L., Seviour, R.J., 2000. The filamentous bacterial morphotype 'Nostocoida limicola'I contains at least two previously described genera in the low G+C gram positive bacteria. Syst. Appl. Microbiol. 23 (4), 528-534.

Liu, J.R., Tanner, R.S., Schumann, P. Weiss, N., McKenzie, C.A., Janssen, P.H., Seviour, E.M., Lawson, P.A., Allen, T.D., Seviour, R.J., 2002. Emended description of the genus Trichococcus, description of Trichococcus collinsii sp. nov., and reclassification of Lactosphaera pasteurii as Trichococcus pasteurii comb. nov. and of Ruminococcus palustris as Trichococcus palustris comb. nov. in the lowG+ C gram-positive bacteria. Int. J. Syst. Evol. Microbiol. 52 (4), 1113.

Liu, Y., Zhang, T., Fang, H.H., 2005. Microbial community analysis and performance of a phosphate-removing activated sludge. Bioresour. Technol. 96 (11), 1205-1214

Martins, A.M.P., Pagilla, K., Heijnen, J.J., van Loosdrecht, M., 2004. Filamentous bulking sludge-a critical review. Water Res. 38 (4), 793-817.

Muller, E.E., Pinel, N., Gillece, J.D., Schupp, J.M., Price, L.B., Engelthaler, D.M., Levantesi, C., Tandoi, V., Luong, K., Baliga, N.S., 2012. Genome sequence of "Candidatus Microthrix parvicella" Bio17-1, a long-chain-fatty-acidaccumulating filamentous actinobacterium from a biological wastewater treatment plant. J. Bacteriol. 194 (23), 6670-6671.

Muszyński, A.M.A., 2016. Differences in populations of filamentous bacteria 
involved in foaming and bulking of activated sludge. Chall. Mod. Technol. 6 (3),

Nielsen, P.H., Kragelund, C., Seviour, R.J., Nielsen, J.L., 2009. Identity and ecophysiology of filamentous bacteria in activated sludge. Fems Microbiol. Rev. 33 (6), 969-998.

Nielsen, P.H., Mielczarek, A.T., Kragelund, C., Nielsen, J.L., Saunders, A.M., Kong, Y. Hansen, A.A., Vollertsen, J., 2010. A conceptual ecosystem model of microbial communities in enhanced biological phosphorus removal plants. Water Res. 44 (17), 5070-5088.

Oehmen, A., Lemos, P.C., Carvalho, G., Yuan, Z., Keller, J., Blackall, L.L., Reis, M.A., 2007. Advances in enhanced biological phosphorus removal: from micro to macro scale. Water Res. 41 (11), 2271-2300.

Patrick, R. Dugan, Daphne, L. Stoner, Pickrum, H.M., 2006. The genus Zoogloea. Prokaryotes 7, 960-970.

Pruesse, E., Quast, C., Knittel, K., Fuchs, B.M., Ludwig, W., Peplies, J., Glöckner, F.O., 2007. SILVA: a comprehensive online resource for quality checked and aligned ribosomal RNA sequence data compatible with ARB. Nucleic Acids Res. 35 (21), 7188-7196.

Ramírez, G.W., Alonso, J.L., Villanueva, A., Guardino, R., Basiero, J.A., Bernecer, I., Morenilla, J.J., 2000. A rapid, direct method for assessing chlorine effect on filamentous bacteria in activated sludge. Water Res. 34 (15), 3894-3898.

Rosselló-Mora, R.A., Wagner, M., Amann, R., Schleifer, K.H., 1995. The abundance of Zoogloea ramigera in sewage treatment plants. Appl. Environ. Microbiol. 61 (2), $702-707$.

Rossetti, S., Tomei, M.C., Nielsen, P.H., Tandoi, V., 2005. "Microthrix parvicella”, a filamentous bacterium causing bulking and foaming in activated sludge systems: a review of current knowledge. Fems Microbiol. Rev. 29 (1), 49-64.

Santos, L.A.D., Ferreira, V., Neto, M.M., Pereira, M.A., Mota, M., Nicolau, A., 2015. Study of 16 Portuguese activated sludge systems based on filamentous bacteria populations and their relationships with environmental parameters. Appl. Microbiol. Biotechnol. 99 (12), 1-10.

Schloss, P.D., Westcott, S.L., Ryabin, T., Hall, J.R., Hartmann, M., Hollister, E.B., Lesniewski, R.A., Oakley, B.B., Parks, D.H., Robinson, C.J., 2009. Introducing mothur: open-source, platform-independent, community-supported software for describing and comparing microbial communities. Appl. Environ. Microbiol.
75 (23), 7537.

Seviour, R.J., Kragelund, C., Kong, Y., Eales, K., Nielsen, J.L., Nielsen, P.H., 2008. Ecophysiology of the Actinobacteria in activated sludge systems. Ant. Van Leeuwenhoek Int. J. General Mol. Microbiol. 94 (1), 21-33.

Sezgin, M., Jenkins, D., Parker, D.S., 1978. A unified theory of filamentous activated sludge bulking. J. Water Pollut. Control Fed. 362-381.

Sokal, R.R., Rohlf, F.J., 1995. Biometry. The Principles \& Practice of Statistics in Biological Research.

Speirs, L.B., Tucci, J., Seviour, R.J., 2015. The activated sludge bulking filament Eikelboom morphotype 0803 embraces more than one member of the Chloroflexi. Fems Microbiol. Ecol. 91 (9).

Stach, J.E.M., Maldonado, L.A., Ward, A.C., Goodfellow, M., Bull, A.T., 2003. New primers for the class Actinobacteria: application to marine and terrestrial environments. Environ. Microbiol. 5 (10), 828-841.

Wágner, D.S., Ramin, E., Szabo, P., Dechesne, A., Plósz, B.G., 2015. Microthrix parvicella abundance associates with activated sludge settling velocity and cheology-Quantifying and modelling filamentous bulking. Water Res. 78, $121-132$.

Wang, J., Li, Q., Qi, R., Tandoi, V., Yang, M., 2014. Sludge bulking impact on relevant bacterial populations in a full-scale municipal wastewater treatment plant Process Biochem. 49 (12), 2258-2265.

Weisburg, W.G., Barns, S.M., Pelletier, D.A., Lane, D.J., 1991. 16S ribosomal DNA amplification for phylogenetic study. J. Bacteriol. 173 (2), 697-703.

Westlund, A., Hagland, E., Rothman, M., 1996. Bulking and foaming caused by microthrix parvicella at three large sewage treatment plants in the greater stockholm area. Water Sci. Technol. 34 (5), 281-287.

Ye, L., Zhang, T., 2013. Bacterial communities in different sections of a municipa wastewater treatment plant revealed by 16S rDNA 454 pyrosequencing. Appl. Microbiol. Biotechnol. 97 (6), 2681-2690.

Ye, L., Shao, M.F., Zhang, T., Tong, A.H.Y., Lok, S., 2011. Analysis of the bacterial community in a laboratory-scale nitrification reactor and a wastewater treatment plant by 454-pyrosequencing. Water Res. 45 (15), 4390-4398.

Zhang, T., Shao, M.F., Ye, L., 2012. 454 Pyrosequencing reveals bacterial diversity of activated sludge from 14 sewage treatment plants. ISME J. 6 (6), 1137-1147. 